\title{
Characterization of Adult Patients who Underwent Orthopedic Surgery in a Tertiary Hospital - A Retrospective Review
}

Silva C.*, Sampaio A. ${ }^{*}$, Marques F.. ${ }^{*}$, Husson N.*, Portugal F.*, Sampaio A. ${ }^{*}$

${ }^{*}$ Centro Hospitalar e Universitário de Coimbra

\section{Background and Goal of Study:}

Nowadays orthopedic surgery is becoming more complex and more frequent. Some of its specific features come from a wide range of ages of its patients: from healthy young people with sports injuries to elderly dependent patients with multiple comorbidities. Therefore, it is important to know the characteristics and specificities of this population in order to optimize its perioperative approach.

The aim of this study is to characterize the patients admitted in a tertiary hospital for orthopedic surgery, analyzing their comorbidities, anesthetic management and the type and time length of surgery.

\section{Material and Methods:}

A retrospective analysis was carried out by reviewing clinical data of 487 patients underwent elective and urgent orthopedic surgery, in our hospital. No exclusion criteria were defined. A retrospective and descriptive analysis was performed.

\section{Results and Discussion:}

\begin{tabular}{c|c|}
\hline Sample & Descriptive analysis \\
\hline Gender & $61,8 \%$ Female \\
\hline Age & $67,1 \pm 19,8$ \\
\hline A.S.A. Classification & $49,9 \%$ A.S.A. II \\
\hline Comorbidities & $\begin{array}{r}\text { Cardiovascular } 51,8 \% \\
\text { Endocrine-metabolic } 46,8 \% \\
\text { Psychiatric 12,5\% } \\
\text { Respiratory } 10,5 \%\end{array}$ \\
\hline
\end{tabular}

\begin{tabular}{|c|c|}
\hline \multicolumn{2}{|c|}{ Surgical procedure } \\
\hline Type & $59,5 \%$ Elective \\
\hline
\end{tabular}

\section{Type of Anesthesia}

General anesthesia

Spinal anesthesia

Combined anesthesia

Peripheral regional anesthesia

Monitored anesthesia care
$74,3 \%$

$15,2 \%$

$4,1 \%$

$3,7 \%$

$1,4 \%$
Length

$61,2 \% 1-2$ hours

74,7\% Lower Limb

18,7\% Upper Limb

Approach

$6,6 \%$ Spine

$6,6 \%$ Bone tumor
Most frequent urgency procedures: fractures of the femur

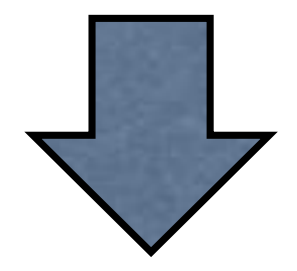

Where the patients with worse physical condition are found
Surgery for bone tumors

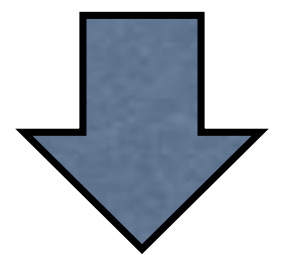

Longest average duration
Regional anesthesia techniques

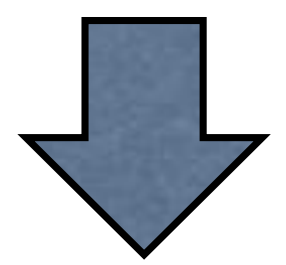

Most often performed for lower limb procedures

\section{Conclusions:}

The elderly patients and the patients proposed for tumor surgery are those who present a greater anesthetic challenge, due to comorbidities and surgical aggressiveness, respectively. Despite the existence of comorbidities, delaying surgical procedures related to trauma is associated with poor results. Regional anesthesia is associated with a fewer odds of adverse outcomes, and should be an option whenever possible.

\section{References:}

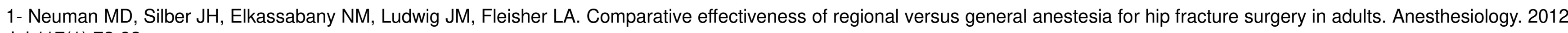
Jul;117(1):72-92

2- Anderson MR, Jeng CL, Wittig JC, Rosenblatt MA. Anesthesia for patients undergoing orthopedic oncologic surgeries. J Clin Anesth. 2010 Nov;22(7):565-72.

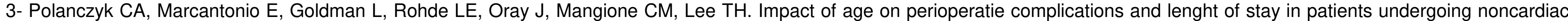

